Food Control

\title{
Spectroscopic approaches for non-destructive shell egg quality and freshness evaluation: opportunities and challenges
--Manuscript Draft--
}

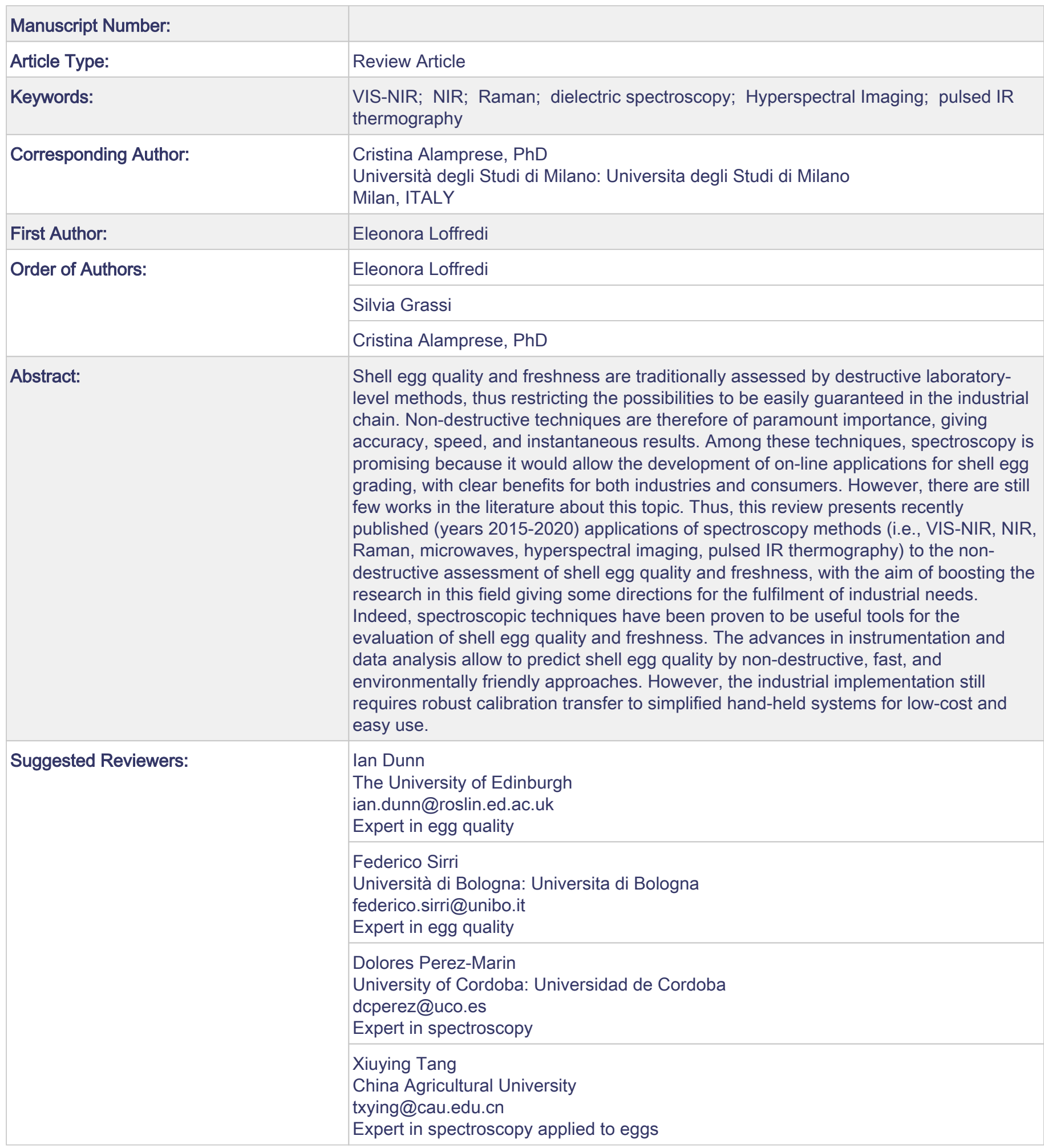


Cristina Alamprese

Food Science and Technology

Tel.: +390250319187

Fax: +390250319190

e-mail: cristina.alamprese@unimi.it

Milan, 12 March 2021

Dear Editor,

Please find a copy of the manuscript "Spectroscopic approaches for nondestructive shell egg quality and freshness evaluation: opportunities and challenges" by Eleonora Loffredi, Silvia Grassi, and Cristina Alamprese we would like to submit for publication in Food Control, as suggested by the Article Transfer Service.

Due to the high perishability of eggs, food industries need fast, reliable, and nondestructive methods for the evaluation of shell egg quality and freshness. Thus, the review presents recently published (years 2015-2020) applications of spectroscopy techniques (i.e., VIS-NIR, NIR, Raman, microwaves, hyperspectral imaging, pulsed IR thermography) to the non-destructive assessment of shell egg quality and freshness, with the aim of boosting the research in this field, giving some directions for the fulfilment of industrial needs.

The work described has not been published previously, is not under consideration for publication elsewhere, and its publication is approved by all authors and tacitly or explicitly by the responsible authorities where the work was carried out; if accepted, it will not be published elsewhere in the same form, in English or in any other language, including electronically without the written consent of the copyright-holder.

Please, do not hesitate to contact me for further information.

Looking forward to hearing from you soon, I remain sincerely yours.

Cristina Alamprese 
1 Spectroscopic approaches for non-destructive shell egg quality and freshness evaluation:

2

3

4

5

6

7

8

9

10 opportunities and challenges

Eleonora Loffredi, Silvia Grassi, Cristina Alamprese*

Department of Food, Environmental, and Nutritional Sciences (DeFENS)

University of Milan, Via G. Celoria 2, 20133 Milan, Italy.

*Corresponding Author: cristina.alamprese@unimi.it 


\section{Abstract}

Shell egg quality and freshness are traditionally assessed by destructive laboratory-level methods, thus restricting the possibilities to be easily guaranteed in the industrial chain. Nondestructive techniques are therefore of paramount importance, giving accuracy, speed, and instantaneous results. Among these techniques, spectroscopy is promising because it would allow the development of on-line applications for shell egg grading, with clear benefits for both industries and consumers. However, there are still few works in the literature about this topic. Thus, this review presents recently published (years 2015-2020) applications of spectroscopy methods (i.e., VIS-NIR, NIR, Raman, microwaves, hyperspectral imaging, pulsed IR thermography) to the non-destructive assessment of shell egg quality and freshness, with the aim of boosting the research in this field giving some directions for the fulfilment of industrial needs. Indeed, spectroscopic techniques have been proven to be useful tools for the evaluation of shell egg quality and freshness. The advances in instrumentation and data analysis allow to predict shell egg quality by non-destructive, fast, and environmentally friendly approaches. However, the industrial implementation still requires robust calibration transfer to simplified hand-held systems for low-cost and easy use.

Keywords: VIS-NIR, NIR, Raman, dielectric spectroscopy, hyperspectral imaging, pulsed IR thermography. 


\section{Introduction}

Eggs are extremely important in human diet because they represent a cheap source of highquality proteins and easily digestible fats, besides representing important ingredients for the food industry thanks to their technological properties (i.e., foaming, gelling, emulsifying). Unfortunately, eggs are highly perishable and quality deterioration occurs during storage, distribution, sale, and processing, altering physical, chemical, nutritional, and sensory properties. Egg quality is a general term including all the characteristics that can affect consumers' acceptability and preference. For egg grading, both external and internal parameters are commonly considered, such as shell features (e.g., cleanliness, strength, texture, and shape), albumen viscosity, and yolk shape and firmness. The interior egg quality begins to deteriorate just after laying through many complex changes, including albumen thinning, $\mathrm{pH}$ increasing, weakening and stretching of the vitelline membrane, and increase in water content of yolk. Thus, freshness plays a major role in the quality perception and consumers usually perceive variability in freshness as a lack of quality (Hisasaga et al., 2020; Karoui et al., 2006). Therefore, the determination of specific parameters for the evaluation of egg freshness and quality has been the major challenge of the last century (Stadelman \& Cotterill, 1995).

Several methods have been developed for the assessment of egg quality and a distinction can be made between destructive and non-destructive methods. Among destructive methods, the most widely used parameters for the determination of egg quality are the shell strength and thickness, the internal air cell size, the albumen/yolk ratio, the albumen viscosity, height, and $\mathrm{pH}$, the yolk colour and shape, and the strength of the vitelline membrane (Karoui et al., 2006; Sharaf Eddin et al., 2019; Stadelman \& Cotterill, 1995). Shell strength and thickness are significantly correlated and associated to egg viability during carriage and storage. These quality parameters are mainly affected by hen breed, age, and nutrition. Fragile eggs not only 
lead to economic loss, but also increase the risk of cracking with subsequent bacterial contamination (Sharaf Eddin et al., 2019). Air cell is formed by the separation of the shell membrane (i.e., the inner and the outer) at the blunt end of an egg, because of the egg content shrinkage during cooling after laying. It enlarges continuously during storage, due to water evaporation and carbon dioxide escape through the eggshell (Stadelman \& Cotterill, 1995). It is affected by egg weight and storage conditions. Air cell height is the only quantitative egg freshness parameter considered by the European Union regulation (Commission Regulation No 589/2008; Karoui et al., 2006). A visible sign of internal quality loss is the albumen thinning mainly due to changes in the ovomucin-lysozyme complex. Albumen freshness is usually measured in Haugh Units (HU), an index proposed in 1937 that consists in measuring the height of the thick albumen at $1 \mathrm{~cm}$ from the yolk, avoiding chalazae, by means of a micrometre mounted on a tripod. A suitable equation allows then the conversion in HU, also considering the egg weight. HU decrease with storage time as a consequence of albumen thinning (Stadelman \& Cotterill, 1995). Another index related to egg freshness is $\mathrm{pH}$. The albumen $\mathrm{pH}$ of newly laid eggs ranges between 7.6 and 8.5. During storage, it increases as a function of environmental conditions due to a loss of carbon dioxide through the shell pores (Karoui et al., 2006). Several changes occur also in the yolk, such as colour modification and shape deformation. Colour is an important acceptability factor to consumers and colour preferences are different across countries (Sharaf Eddin et al., 2019). Changes in shape of the yolk are mainly related to weakening of the vitelline membrane and they can be assessed through the Yolk Index (YI), calculated as the ratio between the yolk height and width (Stadelman \& Cotterill, 1995), or by the Yolk Coefficient (YC), expressed as the ratio between the yolk weight and height (Abdanan Mehdizadeh et al., 2014).

The advantage of destructive analyses is that the measurements are directly performed on the egg fraction of interest, thus providing more reliable data, but they are time-consuming, 
require skilled operators, and can only be applied at laboratory level, thus disregarding the industrial urgent need for fast and reliable methods for the egg quality assessment.

Several studies have been recently focused on the evaluation of different non-destructive techniques for the rapid and reliable determination of quality and freshness of intact food products. One of the most researched field has been the dairy sector, for which Karoui \& De Baerdemaeker (2007) presented an overview of different spectroscopic applications including Near Infrared (NIR), Mid Infrared (MIR), and Front Face Fluorescence (FFF) spectroscopy, as well as stable isotope and Nuclear Magnetic Resonance (NMR). Indeed, these spectroscopic methods guarantee null/low sample preparation and reduce analysis time and costs. Since a huge amount of data is usually generated by these techniques, multivariate statistical methods (i.e., chemometrics) are fundamental for signal elaboration, in order to extract the interesting information (Chen et al., 2019).

NIR spectroscopy has been extensively applied for rapid quality assessment in diverse food product chains. Recent comprehensive reviews report success of this technique in assessing quality parameters in meat (Berri et al., 2019; Dixit et al., 2017), fish (Cheng \& Sun, 2017), and dairy (Pu et al., 2020) products. In the horticultural field, NIR spectral range is often associated with visible spectral region (i.e., VIS-NIR), leading to successful applications for the in-line inspection of agro-food products under semi-industrial conditions (Cortés et al., 2019). Furthermore, technological advances facing size miniaturization, cost reduction, and data analysis are making NIR spectroscopy easily applicable on process lines (Antequera et al., 2021). Raman spectroscopy struggles in food quality applications, due to the presence of many interfering artefacts created by the complex matrices. However, new strategies, such as the Surface Enhanced Raman spectroscopy, improved sensitivity, selectivity, and reproducibility in the determination of quality parameters and contaminants (Lin \& He, 2019). Terahertz spectroscopy, covering a very small range of the electromagnetic spectrum between 
the microwave and infrared regions, has been widely used in the medical field, but novel applications have been recently discussed for quality control both in the agricultural and food industries, as well described in the review by Afsah-Hejri et al. (2019). Similarly, microwave dielectric spectroscopy demonstrated how low-power analytical methodology, based on electromagnetic field in the $0.3-300 \mathrm{GHz}$ frequency range, could be useful for different applications in the food industry thanks to the capability of differentiating materials of different composition (Blakey \& Morales-Partera, 2016).

Analyses of intact foods have been promoted also by coupling spectral and spatial information using Hyperspectral Imaging (HSI) systems. A relevant number of works has been published about the application of HSI systems for food quality evaluation, considering meat (Antequera et al., 2021), fish (Cheng \& Sun, 2017), dairy (Dufour, 2011), and horticultural products (Lu et al., 2020). In most cases, HSI demonstrated to be a reliable tool also for industrial applications. Infrared thermography has been less implemented in food studies, but active thermography, i.e., the generation of a thermal contrast between target and background by an energy source, is drawing attention in food quality control. The few published works in the field have been recently discussed in the review by Ferreira (2020). Based on the above-mentioned promising applications, researchers have evaluated potential of spectroscopic techniques also in the egg field, considering both shell eggs and egg products (Grassi et al., 2018). The main challenge is of course the possibility to unravel shell egg characteristics without breaking the eggs. Thus, this review discusses the recent works about spectroscopy applications for the non-destructive evaluation of shell egg freshness and quality. The considered papers (published in 2015-2020) are summarized in Table 1 and commented hereafter following a technique-wise scheme.

\section{VIS-NIR and NIR spectroscopy}


Interesting applications of transmission VIS-NIR spectroscopy (from 300 to $1100 \mathrm{~nm}$; Fig. 1) for the non-destructive assessment of egg quality and freshness were proposed by Dong et al. (2017a, 2017b, 2018a, 2018b). Spectra were acquired with a fibre probe placed directly on the equatorial region of eggs, reduced in the range $480-960 \mathrm{~nm}$, and pretreated with different methods including Savitzky-Golay smoothing (SG), Multiplicative Scatter Correction (MSC), and Standard Normal Variate (SNV). Partial Least Square Regression (PLSR) was used to build prediction models for eggshell thickness, air chamber diameter, and $\mathrm{pH}$ of albumen and whole egg. In the case of eggshell thickness (Dong et al., 2017b), 70 intact, white-shelled eggs were analysed, including 52 samples in the calibration set and 18 samples in the prediction set. The best correlation coefficients obtained in calibration $\left(r_{c}\right)$ and prediction $\left(r_{p}\right)$ (MSC-treated spectra) were 0.86 and 0.84, respectively, with a Root Mean Square Error in Calibration (RMSEC) and Prediction (RMSEP) of $0.01 \mathrm{~mm}$, over a $0.270-0.378 \mathrm{~mm}$ range of shell thickness measured by a vernier calliper in the equatorial region. For the air chamber diameter (Dong et al., 2018b), 90 brown-shelled eggs were considered, split into a calibration set of 68 eggs and a prediction set of 22 samples. The air chamber diameter, measured by a vernier calliper after shelling, ranged from 15.82 to $35.32 \mathrm{~mm}$. The best PLSR model was obtained with MSC-treated spectra, with a $\mathrm{r}_{\mathrm{c}}$ value of 0.87 and a RMSEC value of $2.13 \mathrm{~mm}$, and $\mathrm{r}_{\mathrm{p}}$, RMSEP values of 0.85 and $2.14 \mathrm{~mm}$, respectively. Albumen and whole egg $\mathrm{pH}$ are considered freshness markers. Indeed, albumen $\mathrm{pH}$ increases during egg storage because of the gaseous exchanges with ambient air through shell pores, and the water and mineral migration between albumen and yolk through vitelline membrane. Prediction models were built by Dong et al. (2017a) on 178 white-shelled eggs stored for different periods (up to 3 weeks) under controlled temperature and Relative Humidity $(\mathrm{RH})$ conditions $\left(30^{\circ} \mathrm{C}, 65 \%\right.$ $\mathrm{RH})$. During storage, $\mathrm{pH}$ changed from 8.08 to 10.11 for albumen and from 7.06 to 8.76 for whole egg. In this case, the reduced spectral range was 550-850 nm. For albumen $\mathrm{pH}$, the 
PLSR model developed with SNV-preprocessed spectra got the best correlation coefficient in prediction $\left(\mathrm{r}_{\mathrm{p}}=0.923\right)$, with a RMSEP of 0.17 . The whole egg $\mathrm{pH}$ model yielded a lower prediction accuracy, with a $r_{p}$ of 0.752 and a RMSEP of 0.27 , maybe due to the smaller variation in $\mathrm{pH}$ data.

Similar results for the air chamber height prediction were obtained by Aboonajmi et al. (2016), applying VIS-NIR spectroscopy to 300 eggs stored in different conditions (temperatures of 25 and $5{ }^{\circ} \mathrm{C}$, with $\mathrm{RH}$ of $40 \%$ and $75 \%$ respectively, up to 30 days). Spectral data were corrected for both multiplicative and additive effects due to scattering, reduced in dimension by applying the Principal Component Analysis (PCA), and then elaborated by an Artificial Neural Network (ANN) algorithm (i.e., radial basis function) internally validated by cross-validation $(\mathrm{CV})$. Values of coefficient of determination $\left(\mathrm{R}^{2}\right)$ in $\mathrm{CV}$ were 0.844 and 0.835 for the eggs stored at 5 and $25^{\circ} \mathrm{C}$, respectively. No information about predictive errors were reported. The authors also measured the HU, obtaining $\mathrm{R}^{2}$ of 0.767 and 0.745 in $\mathrm{CV}$. The observed differences between the room and cold temperature datasets were ascribed to the albumen viscosity change, which can have affected the results. Thus, potential of the spectroscopic technology for a rough screening was demonstrated, but further research on the optic fibre used are suggested. Of course, also the combination of data in a single model and an external validation can contribute to a higher robustness of the proposed procedure. Indeed, Akowuah et al. (2020) encouraged the development of a predictive model for HU and marked date of lay considering different storage conditions, because they observed that HU of eggs stored at low temperature were not directly correlated with storage time (at least in the limited period of their measurements). Thus, in order to provide consumers with the real length of storage, information about the environment conditions is important. In their study, 120 brown-shelled eggs were used, stored under cold $\left(4{ }^{\circ} \mathrm{C}\right)$ and ambient temperature $\left(28{ }^{\circ} \mathrm{C}\right)$ up to 20 days and analysed with a handheld NIR device working in the range 740-1070 nm. 
After MSC pretreatment, classification models were developed for the two storage temperatures applying the Linear Discriminant Analysis (LDA) and dividing samples in four classes based on storage duration. An average correct classification rate in prediction of $96 \%$ and $100 \%$ was obtained for cold and ambient storage, respectively. For predicting the storage duration, the authors developed also a PLS model, reaching $r_{p}$ values of 0.89 and 0.91 for ambient and cold storage, respectively, with RMSEP of 3 and 2.5 days.

The same handheld NIR spectrometer was already used by Coronel-Reyes et al. (2018) for the determination of egg storage time (up to 21 days), considering only room temperature $\left(23^{\circ} \mathrm{C}\right.$, $90 \%$ RU) and a total of 30 eggs. Several preprocessing methods and ANN algorithms were tested and cross-validated. The best model was obtained by SG preprocessing and an ANN with ten neurons in one hidden layer, achieving in prediction a $R^{2}$ of 0.873 and a RMSECV of 1.97 days. Even if the considered number of samples was very small, the work showed the potential of a portable and low-cost NIR device that can be even connected to a smartphone for a rapid response about egg freshness.

The potential of VIS-NIR spectroscopy in investigating shell egg internal quality was studied also for the evaluation of yolk viscosity. Apparent yolk viscosity in lightly heated shell eggs was targeted in the study of Kuroki et al. (2017) as this parameter is an important quality attribute related to textural preference and usage suitability to several dishes. The egg albumen begins denaturing at a lower temperature than the yolk, thus increasing turbidity and possibly masking the variation in transmittance spectra due to increment in yolk viscosity. In this study, 88 white-shelled eggs were cooked by far-infrared heating, under seven different conditions identified with levels from 1 to 7 as a function of the heat intensity. Then, the samples were stored overnight at $20{ }^{\circ} \mathrm{C}$ and the transmittance spectra were acquired in three points along the equatorial region by an optic fibre in the 588-1084 $\mathrm{nm}$ range. After spectra acquisition, the samples were broken and the apparent yolk viscosity was measured with a 
portable falling-needle viscometer, registering a range of approximately $200-600000 \mathrm{mPa}$. Before multivariate analysis, spectra were pretreated using SG and the second derivative (d2). A PCA was used to investigate the relations between the spectral variation of whole shell eggs and the degree of cooking. It was demonstrated that $85 \%$ of the spectral variation of the heated shell eggs resulted from change in the interaction between water and ovotransferrin in egg white. A model for the prediction of yolk viscosity was subsequently developed by PLSR, obtaining a $\mathrm{R}^{2} \mathrm{CV}$ value of 0.81 with a RMSECV of $0.49 \log \mathrm{mPa} \cdot \mathrm{s}$. The model was then judged as "usable for sample screening". A variable selection was then performed by applying the Martens uncertainty test, obtaining an "excellent predictive model” with $\mathrm{R}^{2} \mathrm{CV}=0.89$ and $\mathrm{RMSECV}=0.37 \log \mathrm{mPa} \cdot \mathrm{s}$. The selected wavelengths were in the range $600-850 \mathrm{~nm}$, and the authors demonstrated that those features did not contain the information about thermal gelation of egg albumen. Thus, the model obtained after variable selection was considered robust and independent from the egg white gelation status. However, an external validation of the model was not carried out.

Any change in specific instrument or sample orientation/variety/colour used for model development might influence predictive abilities and results. For instance, Dong et al. (2018a) evaluated the egg orientation effect during non-destructive measurements by means of VISNIR spectroscopy. For this purpose, transmission spectra $(340-1030 \mathrm{~nm})$ were acquired from both the equatorial and blunt region of 91 white-shelled eggs before the destructive evaluation of HU, YI, and albumen pH. A PLSR was employed for modelling the freshness parameters, after SG, MSC, SNV, first and second derivative pretreatments on the spectra. The results obtained from the equatorial region showed higher correlation coefficients in prediction compared to those of the blunt end (i.e., 0.881 vs. 0.813 for HU, 0.855 vs. 0.848 for YI, and 0.888 vs. 0.857 for albumen pH), with lower RMSEP (i.e., 7.720 vs. 9.576 for HU, 0.034 vs. 0.039 for YI, and 0.147 vs. 0.126 for albumen $\mathrm{pH}$ ). These results might be explained by the 
presence of the air chamber in the blunt end, which may affect spectra collection; moreover, the eggshell has more homogeneous texture and thickness in the equatorial region. Eggshell colour can also play an important role in spectral results, mainly when the visible region is included in the analysis. For this reason, many studies on egg freshness evaluation involve only white-shelled eggs, possibly because brown-shelled eggs have limitations due to the interference of spectral bands. However, it could be advisable to consider both the shell egg types to assess spectroscopic method reliability on a larger scale. Eggshell colour is mainly related to the hen breeds and the main pigment comes from protoporphyrin IX in haemoglobin. Eggs with different colours can show no obvious differences in nutritional value or composition. Thus, some authors tried different approaches to manage differences linked to shell colour. For instance, Dong et al. (2019) developed predictive models for albumen $\mathrm{pH}$ considering both white- and brown-shelled eggs. A total of 192 eggs, 96 from White Leghorns hens and 96 from Bantam hens, were purchased and then stored under controlled conditions $\left(30^{\circ} \mathrm{C}, 60 \% \mathrm{RH}\right)$ up to three weeks, in order to promote $\mathrm{pH}$ changes (from 8.24 to 9.76). Eggs were sampled every two days, carrying out both non-destructive VIS-NIR (340-1030 nm) analysis and destructive measurements of albumen $\mathrm{pH}$. After combining the Mahalanobis distance with PCA in order to eliminate outliers, the 167 remaining spectra were pretreated with different methods (SG, MSC, SNV, first and second derivatives), and PLSR models were developed separately or jointly for the eggs of the two hen breeds. For the White Leghorn eggs, the best prediction model was obtained with MSC pretreatment, resulting in $\mathrm{r}_{\mathrm{p}}=0.907$ and $\mathrm{RMSEP}=0.123$. Similar results were obtained also for Bantam eggs, with $r_{p}=0.947$ and RMSEP $=0.115$. However, prediction of albumen $\mathrm{pH}$ for the eggs obtained by the two hen breeds exchanging predictive models was not reliable, resulting in low $r_{p}(0.6-0.7)$ and high $\operatorname{RMSEP}(0.5-0.8)$, maybe related to the different eggshell colour. The issue was solved by an updated global calibration considering all the 
eggs together and applying a slope/bias correction, thus obtaining a $r_{p}$ of 0.908 and a RMSEP of 0.133 . The work demonstrated that the variability related to different egg types should be considered in the model calibration to obtain good prediction ability.

NIR spectroscopy can also be applied to authenticity issues. For instance, Chen et al. (2019) explored the combination of NIR spectroscopy, Joint Mutual Information (JMI) variable selection, and Data Driven-based Class-Modelling (DDCM) for non-destructive discrimination of eggs laid by hens reared in a natural environment (named "native eggs") from eggs obtained in two different industrial systems ("feed eggs"). A total of 122 samples were considered and analysed by NIR spectroscopy $\left(10000-4000 \mathrm{~cm}^{-1}\right)$, using an optic fibre probe in reflectance mode. After SNV pretreatment, the variable selection based on JMI algorithm picked out 20 informative variables over the 1557 original wavenumbers. The DDCM algorithm was then applied for class-modelling, dividing samples in calibration and test sets. The results showed that when "native eggs" were the target class, sensitivity in calibration was $93.3 \%$, while sensitivity and specificity in prediction were $100 \%$ and $98.8 \%$, respectively. The authors considered the model satisfactory. However, due to the limited number of analysed samples that can strongly affect classification model performance, they suggested further research in the field of egg authentication.

\section{Raman spectroscopy}

Raman spectroscopy (Fig. 2) has found limited applications in non-destructive evaluation of egg freshness and quality. Liu et al. (2020) proposed Raman spectroscopy to detect in a simple, fast, and non-destructive way cuticle modifications, correlated to freshness parameters. Indeed, the egg cuticle is a protein layer covering eggshell surface, which deteriorates with storage time and can thus indicate egg freshness. Raman spectra (100-3000 $\left.\mathrm{cm}^{-1}\right)$ of $125 \mathrm{Hy}$-Line Brown eggs stored under controlled conditions $\left(20{ }^{\circ} \mathrm{C}, 40 \% \mathrm{RH}\right)$ up to 
59 days were collected on the top (pointed area), bottom (blunt area), and equatorial regions, with a $6 \mathrm{~mm}$ distance between the probe and the eggshell surface. HU, YI, albumen $\mathrm{pH}$, and air chamber height and diameter were analysed by the common destructive methods. Different preprocessing algorithms were applied to Raman spectra: SG, normalization (NL), first and second derivatives, baseline correction (BL), SNV, MSC, and denoise. Afterwards, PLSR models were developed for all the freshness indicators, using $80 \%$ of the samples as the calibration set and $20 \%$ as the prediction set. Good results were obtained for HU, albumen $\mathrm{pH}$, and air chamber dimensions, with $\mathrm{r}_{\mathrm{p}}$ ranging from 0.807 to 0.895 . YI was not satisfactorily predicted, reaching a maximum value of $r_{p}$ of 0.540 with spectra transformed in second derivative. This result can be due to a weak relationship between the changes in eggshell surface and yolk. Moreover, an evaluation of the best acquisition area was carried out, demonstrating that the prediction performance of the PLSR model established by the top Raman spectrum was relatively better for the considered freshness parameters, increasing values of $r_{p}(0.830-0.935)$. This can be due to the absence of an air chamber in the top of the egg, leading to a constant contact of the egg content with the eggshell. In order to increase the adaptability of the models and maximize Raman spectroscopy application, other influencing factors should be considered, such as breed, hen age, and rearing systems.

\section{Dielectric spectroscopy}

Few attempts to apply dielectric methods (Fig. 3) for non-destructive measurement of various quality indices of shell eggs have been recently published (Akbarzadeh et al., 2019; Soltani et al., 2015; Soltani \& Omid, 2015). Akbarzadeh et al. (2019) aimed to develop a microwave spectroscopy approach based on a waveguide and network analyser instrument for the nondestructive prediction of several egg freshness indices, including air chamber height, thick albumen height, HU, albumen pH, and YC. White-shelled eggs (244 samples) were used, 
stored at room temperature $\left(25^{\circ} \mathrm{C}\right)$ up to 24 days. The average reflection and transmission spectra were obtained in the $0.9-1.7 \mathrm{GHz}$ microwave range, immediately before the destructive evaluation of freshness parameters. Then, regression and classification models were developed and validated, applying different chemometric methods. Generally, the return loss reflection spectra gave the best predictive models for all quality indices, except for albumen pH, with a Residual Prediction Deviation (RPD) over 2. In particular, RPD was close to 3 for the air chamber height. RPD is the ratio of standard deviation to RMSEP and it is used as a performance index of the developed models. Higher RPD values represent strong calibration models since they are obtained with RMSEP lowering and standard deviation increasing. Hence, RPD values higher than 2 or 3 indicate good or excellent calibrations, respectively. When ANN was used for regression purposes, the best predictive models were obtained considering different input spectra. Anyway, also with this algorithm, RPD values were higher than 2 for all the freshness parameters, except for $\mathrm{pH}$ albumen (RPD $=1.83$ ). Good results were obtained also in classification by applying the Soft Independent Modelling of Class Analogy (SIMCA) or the ANN algorithm. Considering six different classes of freshness, the best discrimination power was provided by the return loss reflection spectra, with a total accuracy of $100 \%$. In conclusion, despite the good results obtained, the authors highlighted the necessity to develop a more economical system, since the network analyser used was expensive, and to implement the technique for on-line applications.

The range of radio frequency $(40 \mathrm{kHz}-20 \mathrm{MHz})$ was investigated by Soltani \& Omid (2015) and Soltani et al. (2015) in order to build a robust model for non-destructive classification of eggs based on freshness. In the work by Soltani \& Omid (2015), several machine learning techniques were coupled with dielectric spectroscopy, including ANN, Support Vector Machine (SVM), Bayesian Networks (BN), and Decision Tree (DT). Moreover, a Correlation-based Feature Selection (CFS) was applied to spectra, thus reducing the size of 
feature vector from 387 to 24 . A total of 150 white-shelled eggs were used (i.e., 110 samples in the calibration set and 40 samples in the prediction set), stored for different periods (up to 24 days) at $20{ }^{\circ} \mathrm{C}$ and $35 \% \mathrm{RH}$. All the machine learning techniques resulted in $100 \%$ classification accuracy, except for DT that reached 87.5\%. ANN, SVM, and DT were applied also in regression, in order to predict the air cell height. Good performances were calculated for all the developed models, but the lowest errors were obtained with a Meta-Super-Peer DT $(\mathrm{RMSEP}=1.043 \mathrm{~mm})$

In the work by Soltani et al. (2015), a Multilayer Perceptron Feedforward Neural Network was applied, combined with Levenberg-Marquardt algorithm for error minimization.

Considering HU, YI, yolk/albumen ratio, and yolk weight as quality factors of eggs (287 white-shelled eggs, stored at $20{ }^{\circ} \mathrm{C}$ and $35 \% \mathrm{RU}$ up to 24 days) the following $\mathrm{R}^{2}$ in validation were achieved: $0.998,0.998,0.998$, and 0.994 , respectively. In prediction mode, the mean absolute percent errors obtained were $5.41,6.84,8.79$, and $4.24 \%$ for HU, YI, yolk/albumen, and yolk weight, respectively.

\section{Hyperspectral Imaging}

Coupling spectral and spatial information can be a successful strategy for non-destructive evaluation of food quality on industrial lines. Different works recently demonstrated the potential of HSI (Fig. 4) as a rapid online system for the egg classification based on freshness. Yao et al. (2020) proposed a solution implementing VIS-NIR-HSI for egg classification based on HU. They measured 188 eggs at three freshness grades, acquiring images in the 400-1000 nm spectral range and using a Region of Interest (ROI) of $32 \times 32$ pixel from the centre of the samples. An average spectrum was then calculated for each sample and different variable selection strategies were adopted. Among them, the iteratively retains informative variables algorithm, based on binary matrix shuffling filter, in combination with genetic algorithm gave 
the most promising classification accuracy for the classification models developed by SVM.

Indeed, the calibration and prediction classification accuracies were 99.29 and $97.87 \%$, respectively.

Similarly, Suktanarak \& Teerachaichayut (2017) proposed the use of reflectance NIR-HSI for prediction of HU. The samples (91 eggs) were divided into 7 groups as a function of storage time (up to 21 days) at $25^{\circ} \mathrm{C}$. NIR-HSI data were acquired in reflectance mode (wavelength range, $900-1700 \mathrm{~nm}$ ), considering a ROI of $50 \times 90$ pixel at the centre of each egg image. An average spectrum was calculated for each sample and used for PLSR modelling. The model was calibrated considering 58 eggs and tested for prediction by using the other 33 samples. An excellent performance in prediction was reached by SNV spectral pretreatment, with a $\mathrm{R}^{2} \mathrm{P}$ of 0.85 , a RMSEP of $6.29 \mathrm{HU}$, and a RPD of 3.07. Furthermore, the authors proposed a pixel by pixel distribution maps of $\mathrm{HU}$, thus giving the possibility to evaluate egg freshness by a simple visual inspection according to an intensity scale.

Different factors can affect HSI results, such as the incident light angle and the number of wavelengths. Dai et al. (2020) studied the influence of incident angles on the accuracy of egg HU prediction. Evaluating 350 eggs, and considering scattering, transmission, and mixed hyperspectral images, they found that the accuracy was higher (up to 100\%) with scattering images and inversely proportional to the incident angle. In particular, the best classification model for egg freshness prediction was developed by merging multiple weak classifiers (i.e., Discriminant Analysis Classifier, K-Nearest Neighbour and Random Forest) into a strong classifier by Stacking Ensemble Learning. The model was based on feature wavelengths extracted by Successive Projections Algorithm (SPA) from spectra collected with $0^{\circ}$ incident light and transformed by MSC. Also Zhang et al. (2015) applied a wavelength optimization by SPA, thus selecting only thirteen features in the range $380-1010 \mathrm{~nm}$ to predict HU based on a Support Vector Regression model. Wavelength selection increased $\mathrm{R}_{\mathrm{p}}^{2}$ from 0.85 to 0.87 , 
while reducing RMSEP from 4.33 to 4.01 HU. Although only a small improvement was obtained, the reduction of the wavelengths paves the way to the construction of simpler and cheaper NIR-HSI systems, suitable also for industrial applications. Moreover, the authors demonstrated that HSI can be useful in discovering internal defects, such as scattered yolk and the presence of air bubbles, with an accuracy in prediction of 90.0 and $96.3 \%$, respectively.

NIR-HSI was proposed also to predict S-ovalbumin content (Fu et al., 2019), which is highly correlated with storage time and has low natural variability. It is a promising and significant shell egg freshness index, generated during storage from ovalbumin, the most abundant protein of eggs. The conversion of ovalbumin into the more heat stable S-ovalbumin is affected by $\mathrm{pH}$ and temperature, but it does not change depending on breed, hen age, and nutritional status, thus showing high repeatability (Huang et al., 2012). A total of 108 brownshelled eggs stored up to 41 days at $22{ }^{\circ} \mathrm{C}$ and $65 \%$ RU were analysed in transmission mode with a wavelength range of 300-1100 nm (Fu et al., 2019). In this case, an average spectrum was calculated considering as ROI the entire egg area. Spectra were pretreated by a min-max normalisation. Furthermore, a variable selection strategy was implemented by SPA in order to consider a reduced number of wavelengths (i.e., 12) related to S-ovalbumin content. The PLSR and Multiple Linear Regression (MLR) models were developed using two-thirds of the samples (i.e., 72 eggs), selected using the joint $x-y$ distance method, for calibration, and the remaining samples (i.e., 36 eggs) for the prediction step. The S-ovalbumin fraction analysed by the classical chemical method had a range of about $20-100 \%$. The best PLSR model gave a $\mathrm{r}_{\mathrm{p}}$ of 0.87 , a RMSEP of $0.14 \%$, and a RPD of 1.87 . Even better model performances were obtained by MLR with a $r_{p}$ of 0.91 , a RMSEP of $0.12 \%$, and a RPD of 2.35 . Furthermore, a visualisation of S-ovalbumin fraction distribution was proposed by a distribution map. 
Raman Hyperspectral Imaging (RHSI) has been also applied to the non-destructive evaluation of egg quality. In particular, a recent study by Joshi et al. (2020) applied Raman spectroscopy and RHSI to the identification of "fake eggs". Cases of imitation or "fake food" materials are a major economic fraud for both the food industry and the final consumer. These products are obtained by the incorporation of lower quality or cheaper alternative ingredients that in some cases are not edible nor safe for consumption. The case of fake eggs is only one of the major food frauds of the last few years, prepared using harmful additives, with no nutritional value and difficult to identify by eye. Raman spectroscopy in the $1800-600 \mathrm{~cm}^{-1}$ range and RHSI in the $1500-390 \mathrm{~cm}^{-1}$ range were able to identify differences linked to the materials used in the preparation of fake eggs (i.e., sodium alginate, tartrazine dye, calcium chloride, gypsum powder, and paraffin wax). In addition, RHSI had the advantage of speed, because a large number of samples can be scanned at one time. In this study, 40 samples ( 20 real and 20 fake) of shell eggs, albumen, and yolk were analysed and divided in calibration set (24 samples) and validation set (16 samples). A PLS-Discriminant Analysis (PLS-DA) was used for a classification after MSC preprocessing. For all the types of sample considered, a perfectly accurate (100\%) discrimination between real and fake samples was obtained. Moreover, the fluorescence corrected egg images, generated by selecting in the acquired RHSI images a single band of the chemical of interest (i.e., the Raman peak at $1295 \mathrm{~cm}^{-1}$ ), provided a simple visualization method for the distinction of real and fake samples.

In conclusion, the different approaches indicated that hyperspectral imaging technology could be a feasible solution for the detection of freshness and quality of shell eggs, offering the possibility to develop rapid and simple visualization methods for online screening.

\section{Pulsed infrared thermography}


Pulsed infrared thermography (Fig. 5) is another approach that merges spatial and spectral information. Freni et al. (2018) proposed a methodology for eggs freshness assessment based on active thermography by means of pulsed thermal stimulation in reflection. The authors irradiated samples by means of a xenon flash, which raised up the temperature of the egg of less than $1^{\circ} \mathrm{C}$. The generated thermograms were recorded by means of an IR camera working in the $36000-51000 \mathrm{~nm}$ range and equipped with a synchronization unit that permitted to trigger the acquisition with the generated pulse. Eighteen eggs were stored up to 20 days in a climatic chamber $\left(28^{\circ} \mathrm{C}, 30 \% \mathrm{RH}\right)$ and tested every day by acquiring the heating and cooling profiles. Two thermograms were recorded, corresponding to the two orthogonal sides of the eggs (i.e., frontally and laterally to the dull pole). The IR images clearly showed the air chamber at the dull pole; moreover, they allowed to immediately identify possible anomalies in the egg structure that are not visible to the naked eye, thus providing a powerful tool for checking egg quality. The thermal images were then preprocessed to reach a proper air chamber segmentation by applying the Wiener filter and the top hat operator followed by morphological opening and closure calculations. From the processed images it was possible to calculate the relative increment of air chamber size during storage. The soundness of the approach relies on the difference in thermal propagation, so that the air chamber appears as an area of different temperature with respect to the liquid part of the egg. However, as suggested also by the authors, a higher number of samples considering higher variability should be tested to validate the reliability of the approach; moreover, prediction models should be developed based on multivariate approaches.

\section{Conclusions}

This review demonstrates that spectroscopic techniques, combined with chemometrics, are useful tools for the evaluation of shell egg quality and freshness. The recent advances in 
instrumentation and data analysis allowed to develop non-destructive, fast, and environmentally friendly approaches. However, all the reviewed studies were carried out at a laboratory level and sometimes only a limited number of samples were analysed. Moreover, many studies did not validate the predictive models with an external test set, thus not confirming the robustness of the calibration. Therefore, there are still some challenges to face for an industrial implementation, such as the use of a large number of samples considering as many sources of variation as possible (e.g., hen breed, hen age, rearing systems, storage conditions), a robust calibration transfer to simplified handheld systems for low-cost and easy use, a reliable on-line set-up of the proposed approaches overcoming possible issues related to the fastness of the industrial lines. Thus, much research work is still needed in order to develop non-destructive methods for the shell egg quality evaluation able to satisfy industrial requirements and this can be done only with a strict cooperation of the scientific and industrial world.

\section{Declarations of interest: none.}

\section{Funding}

This work was supported by the Italian Ministry of Education, Universities and Research through the Program PRIN 2017, Project "Use of Local Chicken Breeds in Alternative Production Chain: Welfare, Quality and Sustainability - LoChAl” [grant number 2017S229WC].

\section{References}

Abdanan Mehdizadeh, S., Minaei, S., Hancock, N. H., \& Karimi Torshizi, M. A. (2014). An intelligent system for egg quality classification based on visible-infrared transmittance 
spectroscopy. Information Processing in Agriculture, 1, 105-114. https://doi.org/10.1016/j.inpa.2014.10.002

Aboonajmi, M., Saberi, A., Abbasian Najafabadi, T., \& Kondo, N. (2016). Quality assessment of poultry egg based on visible-near infrared spectroscopy and radial basis function networks. International Journal of Food Properties, 19, 1163-1172. https://doi.org/10.1080/10942912.2015.1075215

Afsah-Hejri, L., Hajeb, P., Ara, P., \& Ehsani, R. J. (2019). A comprehensive review on food applications of terahertz spectroscopy and imaging. Comprehensive Reviews in Food Science and Food Safety, 18, 1563-1621. https://doi.org/10.1111/1541-4337.12490

Akbarzadeh, N., Mireei, S. A., Askari, G., \& Mahdavi, A. H. (2019). Microwave spectroscopy based on the waveguide technique for the nondestructive freshness evaluation of egg. Food Chemistry, 277, 558-565. https://doi.org/10.1016/j.foodchem.2018.10.143

Akowuah, T. O. S., Teye, E., Hagan, J., \& Nyandey, K. (2020). Rapid and nondestructive determination of egg freshness category and marked date of lay using spectral fingerprint. Journal of Spectroscopy, 2020, 8838542. https://doi.org/10.1155/2020/8838542

Antequera, T., Caballero, D., Grassi, S., Uttaro, B., \& Perez-Palacios, T. (2021). Evaluation of fresh meat quality by Hyperspectral Imaging (HSI), Nuclear Magnetic Resonance (NMR) and Magnetic Resonance Imaging (MRI): A review. Meat Science, 172, 108340. https://doi.org/10.1016/j.meatsci.2020.108340

Berri, C., Picard, B., Lebret, B., Andueza, D., Lefèvre, F., Le Bihan-Duval, E., Beauclercq, S., Chartrin, P., Vautier, A., Legrand, I., \& Hocquette, J. F. (2019). Predicting the quality of meat: myth or reality? Foods, 8, 436. https://doi.org/10.3390/foods8100436 Blakey, R. T., \& Morales-Partera, A. M. (2016). Microwave dielectric spectroscopy - A 
versatile methodology for online, non-destructive food analysis, monitoring and process control. Engineering in Agriculture, Environment and Food, 9, 264-273. https://doi.org/10.1016/j.eaef.2016.02.001

Chen, H., Tan, C., \& Lin, Z. (2019). Non-destructive identification of native egg by nearinfrared spectroscopy and data driven-based class-modeling. Spectrochimica Acta - Part A: Molecular and Biomolecular Spectroscopy, 206, 484-490. https://doi.org/10.1016/j.saa.2018.08.041

Cheng, J.-H., \& Sun, D.-W. (2017). Partial Least Squares Regression (PLSR) applied to NIR and HSI spectral data modeling to predict chemical properties of fish muscle. Food Engineering Reviews, 9, 36-49. https://doi.org/10.1007/s12393-016-9147-1

Commission Regulation (EC) No 589/2008 laying down detailed rules for implementing Council Regulation (EC) No 1234/2007 as regards marketing standards for eggs. Official Journal of the European Union, L163, 6-23. http://data.europa.eu/eli/reg/2008/589/oj

Coronel-Reyes, J., Ramirez-Morales, I., Fernandez-Blanco, E., Rivero, D., \& Pazos, A. (2018). Determination of egg storage time at room temperature using a low-cost NIR spectrometer and machine learning techniques. Computers and Electronics in Agriculture, 145, 1-10. https://doi.org/10.1016/j.compag.2017.12.030

Cortés, V., Blasco, J., Aleixos, N., Cubero, S., \& Talens, P. (2019). Monitoring strategies for quality control of agricultural products using visible and near-infrared spectroscopy: A review. Trends in Food Science and Technology, 85, 138-148. https://doi.org/10.1016/j.tifs.2019.01.015

Dai, D., Jiang, T., Lu, W., Shen, X., Xiu, R., \& Zhang, J. (2020). Nondestructive detection for egg freshness based on hyperspectral scattering image combined with ensemble learning. Sensors, 20, 5484. https://doi.org/10.3390/s20195484

Dixit, Y., Casado-Gavalda, M. P., Cama-Moncunill, R., Cama-Moncunill, X., Markiewicz- 
Keszycka, M., Cullen, P. J., \& Sullivan, C. (2017). Developments and challenges in online NIR spectroscopy for meat processing. Comprehensive Reviews in Food Science and Food Safety, 16, 1172-1187. https://doi.org/10.1111/1541-4337.12295

Dong, X., Dong, J., Li, Y., Xu, H., \& Tang, X. (2019). Maintaining the predictive abilities of egg freshness models on new variety based on VIS-NIR spectroscopy technique. Computers and Electronics in Agriculture, 156, 669-676. https://doi.org/10.1016/j.compag.2018.12.012

Dong, X., Dong, J., Peng, Y., \& Tang, X. (2017a). Comparative study of albumen pH and whole egg $\mathrm{pH}$ for the evaluation of egg freshness. Spectroscopy Letters, 50(9), 463-469. https://doi.org/10.1080/00387010.2017.1360357

Dong, X., Li, Z., Shen, Z., \& Tang, X. (2018a). Non destructive egg freshness assessment from the equatorial and blunt region based on visible near infrared spectroscopy. Spectroscopy Letters, 51(10), 540-546. https://doi.org/10.1080/00387010.2018.1525409

Dong, X., Tang, X., Dong, J., Shen, Z., Li, Y., Peng, Y., \& Li, Y. (2018b). Nondestructive egg freshness assessment of air chamber diameter by VIS-NIR spectroscopy. ASABE Paper No 1801022, St. Joseph, MI: ASABE. https://doi.org/10.13031/aim.201801022

Dong, X., Tang, X., Peng, Y., \& Dong, J. (2017b). Nondestructive assessment of eggshell thickness by VIS/NIR spectroscopy. ASABE Paper No 1700888, St. Joseph, MI: ASABE. https://doi.org/10.13031/aim.201700888

Dufour, É. (2011). Recent advances in the analysis of dairy product quality using methods based on the interactions of light with matter. International Journal of Dairy Technology, 64(2), 153-165. https://doi.org/10.1111/j.1471-0307.2010.00665.x

Ferreira, D. S. (2020). Thermal imaging as a tool in food analysis. Journal of Spectral Imaging, 9, a7. https://doi.org/10.1255/jsi.2020.a7

Freni, F., Quattrocchi, A., Di Giacomo, A., Piccolo, S., \& Montanini, R. (2018). Assessment 
of eggs freshness by means of pulsed infrared thermography. In Proceedings of the 14th Quantitative Infrared Thermography Conference (pp. 632-639). QIRT COUNCIL. Quantitative Infrared Thermography. https://doi.org/10.21611/qirt.2018.068

Fu, D. D., Wang, Q. H., Ma, M. H., Ma, Y. X., \& Vong, C. N. (2019). Prediction and visualisation of S-ovalbumin content in egg whites using hyperspectral images. International Journal of Food Properties, 22, 1077-1086. https://doi.org/10.1080/10942912.2019.1628775

Grassi, S., Vitale, R., \& Alamprese, C. (2018). An exploratory study for the technological classification of egg white powders based on infrared spectroscopy. LWT-Food Science and Technology, 96, 469-475. https://doi.org/10.1016/j.1wt.2018.05.065

Hisasaga, C., Griffin, S. E., \& Tarrant, K. J. (2020). Survey of egg quality in commercially available table eggs. Poultry Science, 99, 7202-7206. https://doi.org/10.1016/j.psj.2020.09.049

Huang, Q., Qiu, N., Ma, M. H., Jin, Y. G., Yang, H., Geng, F., \& Sun, S. H. (2012). Estimation of egg freshness using S-ovalbumin as an indicator. Poultry Science, 91, 739-743. https://doi.org/10.3382/ps.2011-01639

Joshi, R., Lohumi, S., Joshi, R., Kim, M. S., Qin, J., Baek, I., \& Cho, B.-K. (2020). Raman spectral analysis for non-invasive detection of external and internal parameters of fake eggs. Sensors and Actuators B: Chemical, 303, 127243. https://doi.org/10.1016/j.snb.2019.127243

Karoui, R., \& De Baerdemaeker, J. (2007). A review of the analytical methods coupled with chemometric tools for the determination of the quality and identity of dairy products. Food Chemistry, 102, 621-640. https://doi.org/10.1016/j.foodchem.2006.05.042

Karoui, R., Kemps, B., Bamelis, F., De Ketelaere, B., Decuypere, E., \& De Baerdemaeker, J. (2006). Methods to evaluate egg freshness in research and industry: A review. European 
Food Research and Technology, 222, 727-732. https://doi.org/10.1007/s00217-005$0145-4$

Kuroki, S., Kanoo, T., Itoh, H., Ohkawa, Y., \& Kamisoyama, H. (2017). Nondestructive measurement of yolk viscosity in lightly heated chicken shell eggs. Journal of Food Engineering, 205, 18-24. https://doi.org/10.1016/j.jfoodeng.2017.02.030

Lin, Z., \& He, L. (2019). Recent advance in SERS techniques for food safety and quality analysis: a brief review. Current Opinion in Food Science, 28, 82-87. https://doi.org/10.1016/j.cofs.2019.10.001

Liu, Y., Ren, X., Yu, H., Cheng, Y., Guo, Y., Yao, W., \& Xie, Y. (2020). Non-destructive and online egg freshness assessment from the egg shell based on Raman spectroscopy. Food Control, 118, 107426. https://doi.org/10.1016/j.foodcont.2020.107426

Lu, Y., Saeys, W., Kim, M., Peng, Y., \& Lu, R. (2020). Hyperspectral imaging technology for quality and safety evaluation of horticultural products: A review and celebration of the past 20-year progress. Postharvest Biology and Technology, 170, 111318. https://doi.org/10.1016/j.postharvbio.2020.111318

Pu, Y. Y., O’Donnell, C., Tobin, J. T., \& O’Shea, N. (2020). Review of near-infrared spectroscopy as a process analytical technology for real-time product monitoring in dairy processing. International Dairy Journal, 103, 104623. https://doi.org/10.1016/j.idairyj.2019.104623

Sharaf Eddin, A., Ibrahim, S. A., \& Tahergorabi, R. (2019). Egg quality and safety with an overview of edible coating application for egg preservation. Food Chemistry, 296, 2939. https://doi.org/10.1016/j.foodchem.2019.05.182

Soltani, M., \& Omid, M. (2015). Detection of poultry egg freshness by dielectric spectroscopy and machine learning techniques. LWT - Food Science and Technology, 62, 1034-1042. https://doi.org/10.1016/j.lwt.2015.02.019 
604 Soltani, M., Omid, M., \& Alimardani, R. (2015). Egg quality prediction using dielectric and 605 visual properties based on artificial neural network. Food Analytical Methods, 8, 710606 717. https://doi.org/10.1007/s12161-014-9948-x

607 Stadelman, W. J., \& Cotterill, O. J. (1995). Egg Science and Technology (4 ${ }^{\text {th }}$ ed.). 608 Binghamton: The Haworth Press, Inc.

609 Suktanarak, S., \& Teerachaichayut, S. (2017). Non-destructive quality assessment of hens' 610 eggs using hyperspectral images. Journal of Food Engineering, 215, 97-103. https://doi.org/10.1016/j.jfoodeng.2017.07.008

612

Yao, K., Sun, J., Zhou, X., Nirere, A., Tian, Y., \& Wu, X. (2020). Nondestructive detection for egg freshness grade based on hyperspectral imaging technology. Journal of Food Process Engineering, 2020;e13422. https://doi.org/10.1111/jfpe.13422

615

Zhang, W., Pan, L., Tu, S., Zhan, G., \& Tu, K. (2015). Non-destructive internal quality assessment of eggs using a synthesis of hyperspectral imaging and multivariate analysis. Journal of Food Engineering, 157, 41-48.

618 https://doi.org/10.1016/j.jfoodeng.2015.02.013

619 
620 Figure Legends

621 Fig. 1. Block scheme of VIS-NIR spectroscopy.

622

623 Fig. 2. Block scheme of Raman spectroscopy.

624

625 Fig. 3. Block scheme of dielectric spectroscopy.

626

627 Fig. 4. Block scheme of hyperspectral imaging systems.

628

629 Fig. 5. Block scheme of pulsed infrared thermography. 
Table 1.

Spectroscopy techniques applied to the evaluation of quality and freshness of shell eggs.

\begin{tabular}{|c|c|c|c|c|c|}
\hline Analytical technology & Egg parameter & $\begin{array}{l}\text { Number of samples } \\
\text { (eggs) }\end{array}$ & Predictive algorithm & $\begin{array}{l}\text { Accuracy of the best models } \\
\text { obtained for each algorithm }\end{array}$ & Reference \\
\hline \multirow[t]{8}{*}{ VIS-NIR spectroscopy } & Eggshell thickness & $\begin{array}{l}70 \\
(52, \mathrm{C} ; 18, \mathrm{P})\end{array}$ & PLSR & $\mathrm{r}_{\mathrm{C}}=0.86, \mathrm{r}_{\mathrm{P}}=0.84$ & Dong et al. (2017b) \\
\hline & Air chamber diameter & $\begin{array}{l}90 \\
(68, C ; 22, P)\end{array}$ & PLSR & $\mathrm{r}_{\mathrm{C}}=0.87, \mathrm{r}_{\mathrm{P}}=0.85$ & Dong et al. (2018b) \\
\hline & $\begin{array}{l}\text { Air chamber height } \\
\text { Haugh Units }\end{array}$ & $\begin{array}{l}300 \\
\text { (no test set) }\end{array}$ & ANN (RBF) & $\begin{array}{l}\text { Air chamber height: } \\
\mathrm{R}^{2}{ }_{\mathrm{C}}=0.941, \mathrm{R}^{2} \mathrm{CV}=0.844\left(5^{\circ} \mathrm{C}\right) \\
\mathrm{R}^{2}{ }_{\mathrm{C}}=0.918, \mathrm{R}^{2}{ }_{\mathrm{CV}}=0.835\left(25^{\circ} \mathrm{C}\right) \\
\text { Haugh Units: } \\
\mathrm{R}^{2}{ }_{\mathrm{C}}=0.898, \mathrm{R}^{2}{ }_{\mathrm{CV}}=0.767\left(5^{\circ} \mathrm{C}\right) \\
\mathrm{R}^{2}{ }_{\mathrm{C}}=0.871, \mathrm{R}^{2} \mathrm{CV}=0.745\left(25^{\circ} \mathrm{C}\right)\end{array}$ & Aboonajmi et al. (2016) \\
\hline & $\begin{array}{l}\text { Haugh Units } \\
\text { Yolk index } \\
\text { Albumen pH }\end{array}$ & $\begin{array}{l}91 \\
(68, C ; 23, P)\end{array}$ & PLSR & $\begin{array}{l}\text { Equatorial region: } \\
\text { Haugh Units: } \\
\mathrm{r}_{\mathrm{C}}=0.897 ; \mathrm{r}_{\mathrm{P}}=0.881 \\
\text { Yolk Index: } \\
\mathrm{r}_{\mathrm{C}}=0.903 ; \mathrm{r}_{\mathrm{P}}=0.855 \\
\text { Albumen } \mathrm{pH}: \\
\mathrm{r}_{\mathrm{C}}=0.936 ; \mathrm{r}_{\mathrm{P}}=0.888\end{array}$ & Dong et al. (2018a) \\
\hline & Albumen pH & $\begin{array}{l}80 \text { White Leghorns } \\
(53, \mathrm{C} ; 27, \mathrm{P})\end{array}$ & PLSR & $\begin{array}{l}\text { White Leghorns } \\
\mathrm{r}_{\mathrm{C}}=0.918, \mathrm{r}_{\mathrm{P}}=0.907\end{array}$ & Dong et al. (2019) \\
\hline & & $\begin{array}{l}87 \text { Bantam } \\
(58, C ; 29, P)\end{array}$ & & $\begin{array}{l}\text { Bantam } \\
r_{C}=0.955, r_{P}=0.947\end{array}$ & \\
\hline & $\begin{array}{l}\text { Albumen } \mathrm{pH} \\
\text { Whole egg } \mathrm{pH}\end{array}$ & $\begin{array}{l}178 \\
(133, \mathrm{C} ; 45, \mathrm{P})\end{array}$ & PLSR & $\begin{array}{l}\text { Albumen } \mathrm{pH}: \\
\mathrm{r}_{\mathrm{C}}=0.943, \mathrm{r}_{\mathrm{P}}=0.923 \\
\text { Whole egg pH: } \\
\mathrm{r}_{\mathrm{C}}=0.776, \mathrm{r}_{\mathrm{P}}=0.752\end{array}$ & Dong et al. (2017a) \\
\hline & Apparent yolk viscosity & $\begin{array}{l}88 \\
\text { (no test set) }\end{array}$ & PLSR & $\mathrm{R}^{2}{ }_{\mathrm{C}}=-, \mathrm{R}_{\mathrm{CV}}^{2}=0.89$ & Kuroki et al. (2017) \\
\hline
\end{tabular}


LDA

Accuracy $\mathrm{P}=100 \%\left(28^{\circ} \mathrm{C}\right)$ Accuracy $\mathrm{P}=96 \%\left(4{ }^{\circ} \mathrm{C}\right)$
Egg storage time

Native eggs/feed eggs

Air chamber height

Air chamber diameter

Haugh Units

Albumen pH

Dielectric spectroscopy

Air chamber height

Thick albumen height

Haugh Units

Albumen $\mathrm{pH}$

Yolk Coefficient

Freshness

Air cell height

Haugh Units

Yolk/Albumen

Yolk weight

Yolk Index
244

\section{0 \\ (21, C; 9, P)}

112

125

$(100, \mathrm{C} ; 25, \mathrm{P})$

$$
\text { (196, C; 48, P) }
$$

(196, C; 48, P)

150

(110, C; 40, P)

287

$(124, \mathrm{C} ; 163, \mathrm{P})$
ANN

DDCM

PLSR

SIMCA

ANN

SVM

DT

FFNN
$\mathrm{R}^{2} \mathrm{C}=0.865, \mathrm{R}^{2} \mathrm{CV}=0.873$

Sensitivity $\mathrm{P}=100 \%$ Specificity $\mathrm{P}=98.8 \%$

Air chamber height: $\mathrm{rc}=0.828, \mathrm{rp}=0.830$ Air chamber diameter: $\mathrm{rc}=0.903, \mathrm{rp}=0.915$ Haugh Units:

$\mathrm{rc}=0.944, \mathrm{rp}=0.925$

Abumen $\mathrm{pH}$ :

$\mathrm{rc}=0.945, \mathrm{rp}=0.935$

Air chamber height:

$\mathrm{R}^{2}{ }_{\mathrm{C}}=0.900, \mathrm{R}_{\mathrm{P}}^{2}=0.893$

Thick albumen height:

$\mathrm{R}^{2} \mathrm{C}=0.839, \mathrm{R}_{\mathrm{P}}^{2}=0.826$

Haugh Units

$R^{2}{ }_{C}=0.814, R^{2}{ }_{P}=0.804$

Albumen $\mathrm{pH}$

$\mathrm{R}^{2}{ }_{\mathrm{C}}=0.787, \mathrm{R}_{\mathrm{P}}^{2}=0.779$

Yolk Coefficient

$\mathrm{R}^{2}{ }_{\mathrm{C}}=0.883, \mathrm{R}_{\mathrm{P}}^{2}=0.869$

Accuracy $\mathrm{P}=100 \%$

$\mathrm{r}_{\mathrm{P} \text { ANN }}=0.817$

$\mathrm{r}_{\mathrm{P} \mathrm{SVM}}=0.920$

$\mathrm{r}_{\mathrm{P} \text { DT }}=0.906$

Haugh Units:

$\mathrm{R}^{2}{ }_{\mathrm{C}}=0.998, \mathrm{R}_{\mathrm{P}}{ }=0.998$

Yolk/Albumen:

$\mathrm{R}^{2}{ }_{\mathrm{C}}=0.996, \mathrm{R}_{\mathrm{P}}^{2}=0.998$
Coronel-Reyes et al. (2018)

Chen et al. (2019)

Liu et al. (2020)

Akbarzadeh et al. (2019) 


\begin{tabular}{|c|c|c|c|c|c|}
\hline & & & & $\begin{array}{l}\text { Yolk weight } \\
\mathrm{R}_{\mathrm{C}}^{2}=0.994, \mathrm{R}_{\mathrm{P}}^{2}=0.994 \\
\text { Yolk Index: } \\
\mathrm{R}_{\mathrm{C}}^{2}=0.994, \mathrm{R}_{\mathrm{P}}^{2}=0.998\end{array}$ & \\
\hline \multirow[t]{4}{*}{ VIS-NIR-HSI } & Haugh Units & $\begin{array}{l}188 \\
(141, C ; 47, P)\end{array}$ & IRIV-GA-SVM & Accuracy $\mathrm{P}=97.87 \%$ & Yao et al. (2020) \\
\hline & Haugh Units & $\begin{array}{l}350 \\
(200, C ; 150, P)\end{array}$ & SPA-SEL & Accuracy up to $100 \%$ & Dai et al. (2020) \\
\hline & $\begin{array}{l}\text { Haugh Units } \\
\text { Scattered yolk } \\
\text { Air bubbles }\end{array}$ & $\begin{array}{l}645 \\
(200, C ; 150, P)\end{array}$ & SPA-SVR & $\begin{array}{l}\text { Haugh Units: } \\
\mathrm{R}^{2} \mathrm{C}=0.89, \mathrm{R}_{\mathrm{P}}^{2}=0.87 \\
\text { Scattered yolk: } \\
\text { Accuracy }=90 \% \\
\text { Air bubbles: } \\
\text { Accuracy }=96.3 \%\end{array}$ & Zhang et al. (2015) \\
\hline & S-ovalbumin content & $\begin{array}{l}108 \\
(72, C ; 36, P)\end{array}$ & $\begin{array}{l}\text { PLSR } \\
\text { MLR }\end{array}$ & $\begin{array}{l}\text { PLSR: } \\
\mathrm{r}_{\mathrm{C}}=0.929, \mathrm{r}_{\mathrm{P}}=0.875 \\
\text { MLR: } \\
\mathrm{r}_{\mathrm{C}}=0.922, \mathrm{r}_{\mathrm{P}}=0.911\end{array}$ & Fu et al. (2019) \\
\hline NIR-HSI & Haugh Units & $\begin{array}{l}91 \\
(58, C ; 33, P)\end{array}$ & PLSR & $\mathrm{R}_{\mathrm{C}}^{2}=0.91, \mathrm{R}_{\mathrm{P}}^{2}=0.85$ & $\begin{array}{l}\text { Suktanarak \& } \\
\text { Teerachaichayut (2017) }\end{array}$ \\
\hline RHSI & Identification of fake eggs & $\begin{array}{l}120 \\
(72, C ; 48, P)\end{array}$ & PLS-DA & Accuracy $=100 \%$ & Joshi et al. (2020) \\
\hline $\begin{array}{l}\text { Pulsed infrared } \\
\text { thermography }\end{array}$ & Air chamber & $\begin{array}{l}18 \\
\text { (no test set) }\end{array}$ & - & - & Freni et al. (2018) \\
\hline \multicolumn{6}{|c|}{$\begin{array}{l}\text { JIS-NIR, Visible and Near-Infrared; NIR, Near-Infrared; NIR-HIS, Near-Infrared Hyperspectral Imaging; VIS-NIR-HIS, Visible and Near-Infrared } \\
\text { Hyperspectral Imaging; RHSI, Raman Hyperspectral Imaging; C, calibration; P, prediction; PLSR, Partial Least Squares Regression; LDA, Linear Discriminant } \\
\text { Analysis; RBF, Radial Basis function; ANN, Artificial Neural Network; SVM, Support Vector Machine; DT, Decision Tree; DDCM, Data Driven-based Class- } \\
\text { Modelling; FFNN, Feedforward Neural Network; SIMCA, Soft Independent Modelling of Class Analogy; SPA-SEL, Successive Projection Algorithm- } \\
\text { tacking Ensemble Learning; SPA-SVR, Successive Projection Algorithm-Support Vector Regression; MLR, Multiple Linear Regression; r, coefficient of } \\
\text { orrelation: CV. Cross-Validation: RPD, Residual Prediction Deviation: R². coefficient of determination. }\end{array}$} \\
\hline
\end{tabular}


Figure 1

Light source

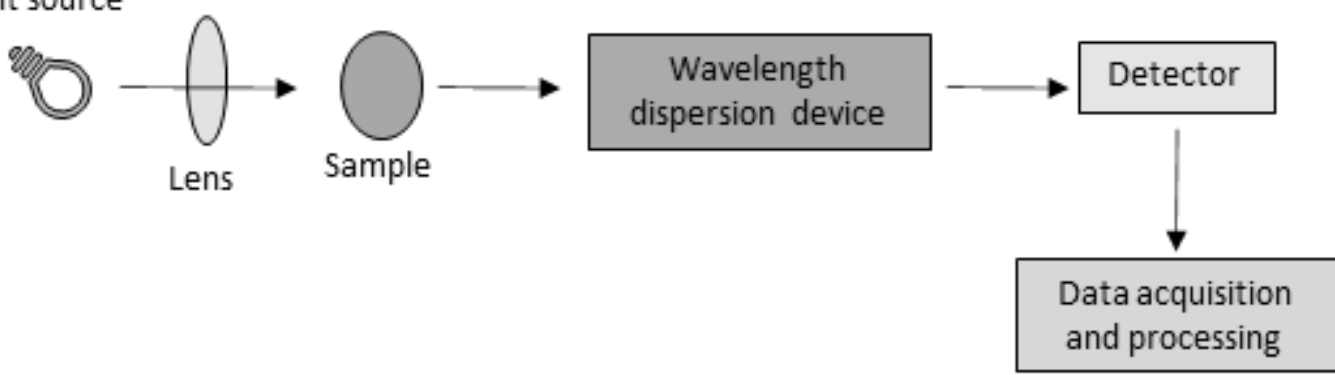

Figure 1 - Color version for online only

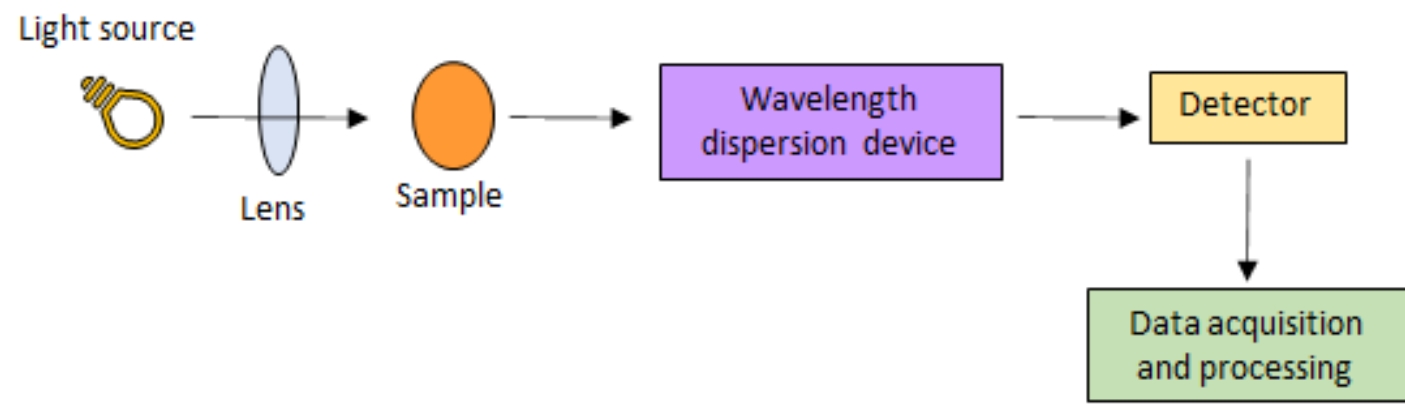


Figure 2

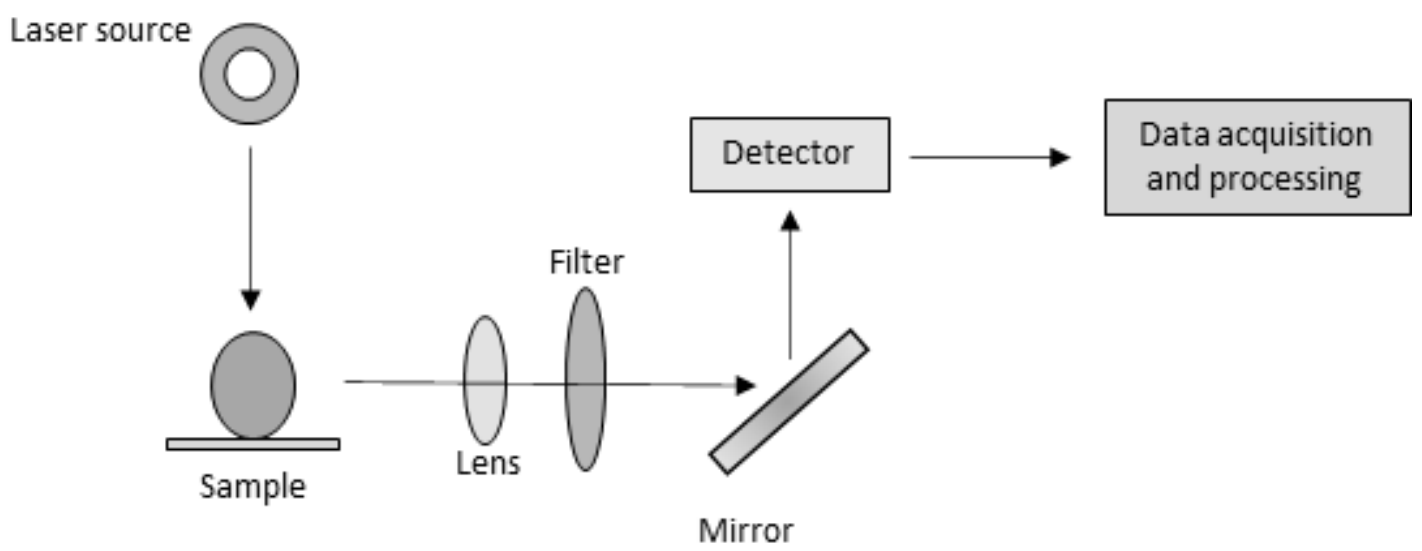

Figure 2 - Color version for online only

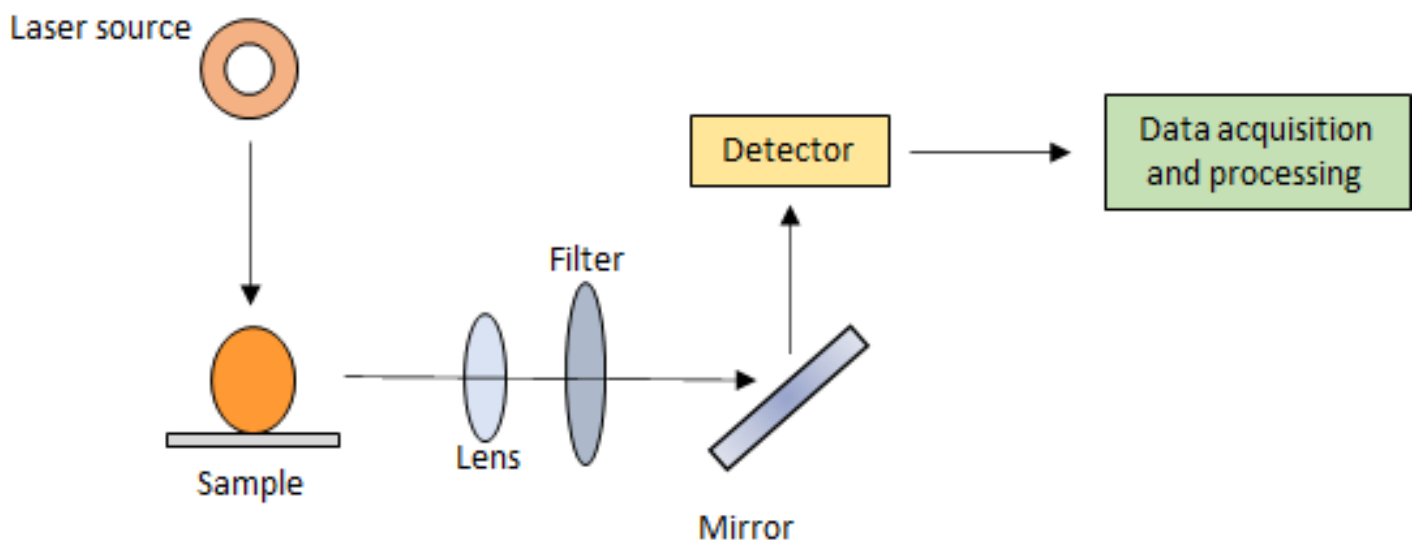


Figure 3

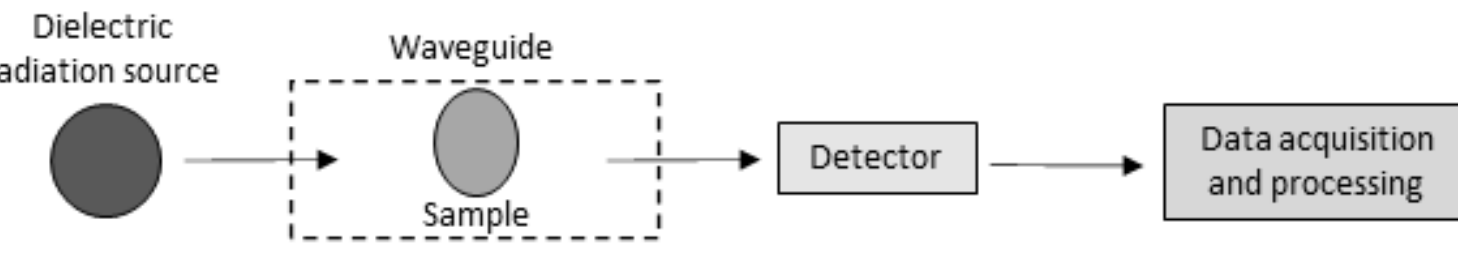

Figure 3 - Color version for online only

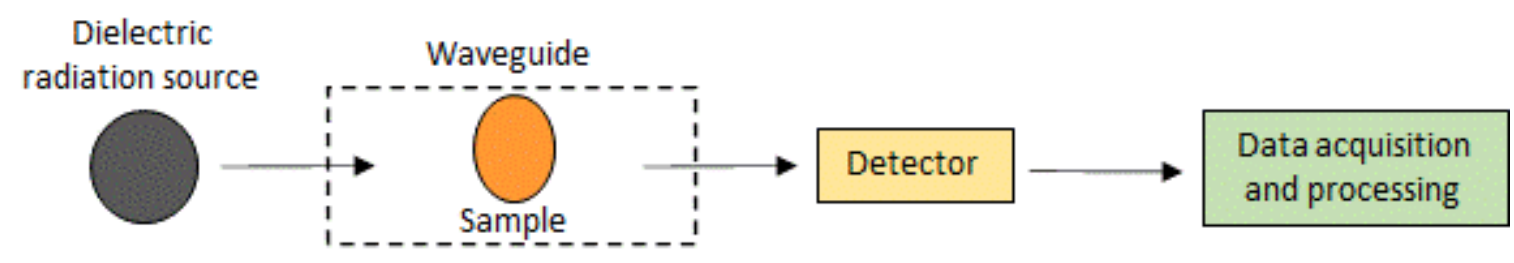


Figure 4

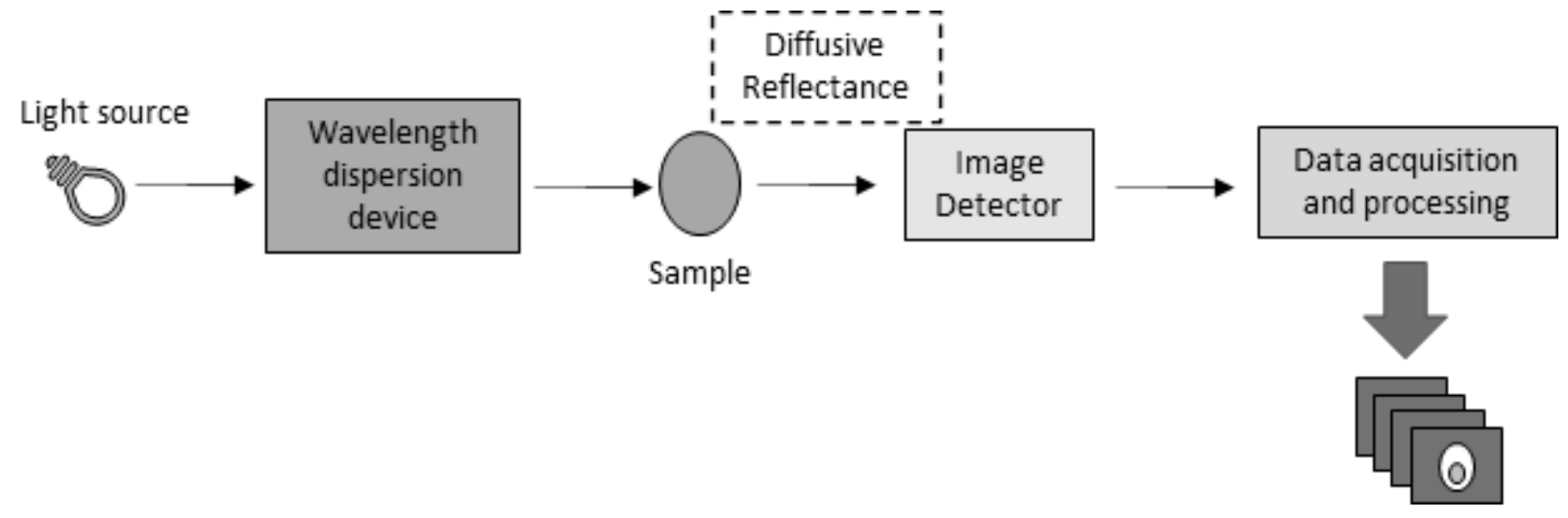

Figure 4 - Color version for online only

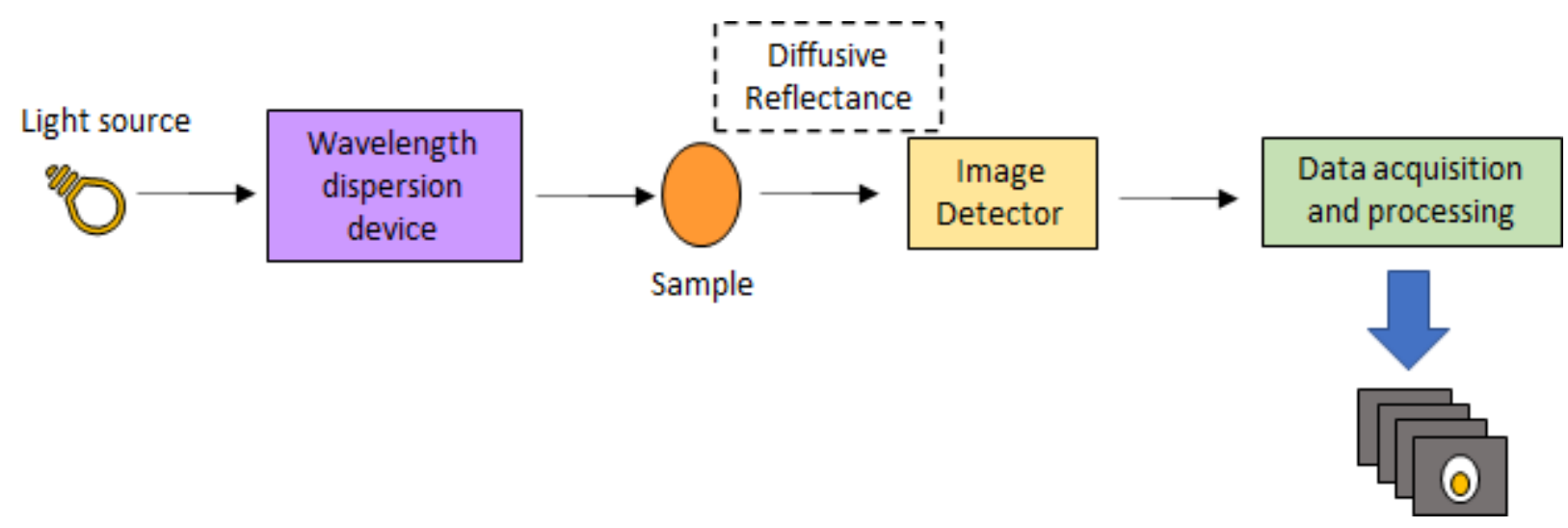


Figure 5

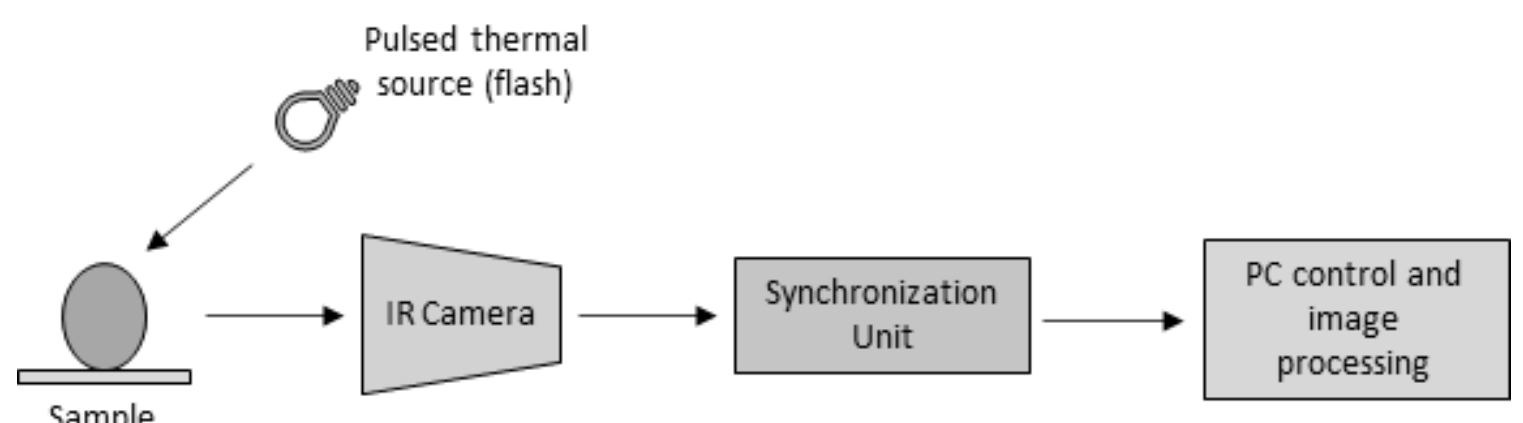

Figure 5 - Color version for online only

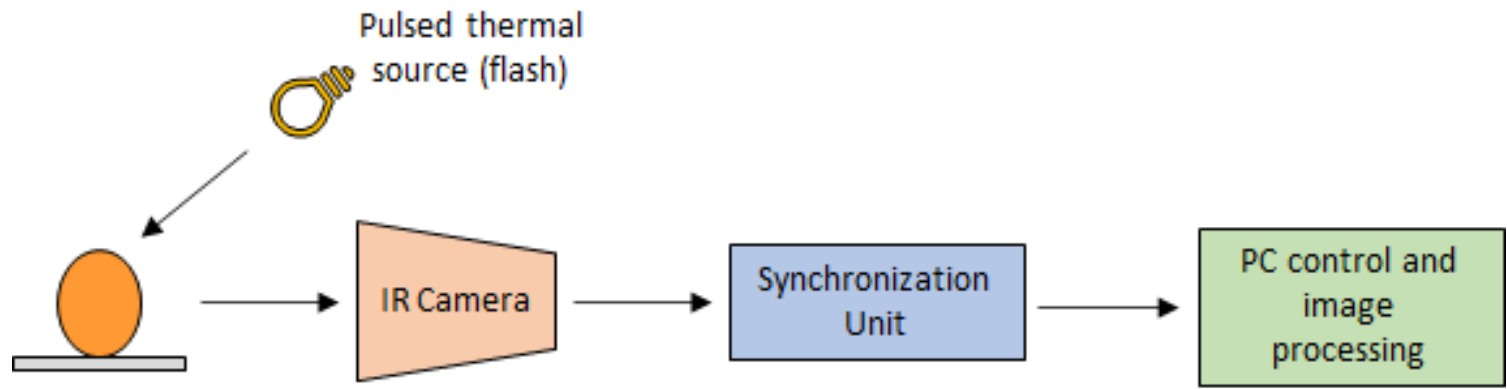

Sample 


\section{Highlights}

- Food industries need non-destructive methods for shell egg quality evaluation.

- Recent applications of spectroscopy to egg quality assessment are reviewed.

- Spectroscopic techniques are useful tools for egg quality and freshness evaluation.

- The industrial implementation still presents some challenges to be faced. 


\section{Graphical abstract}

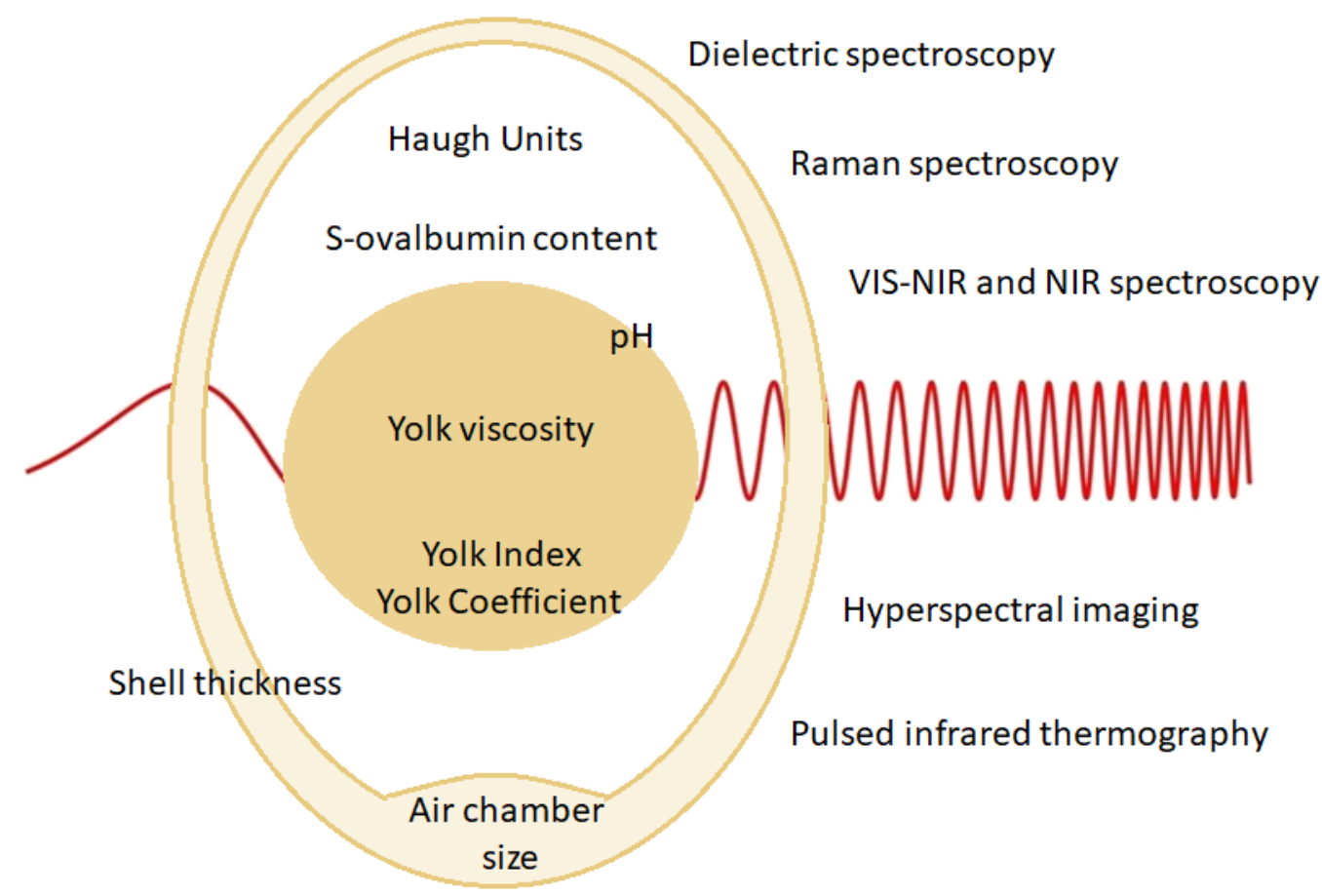




\section{Declaration of interests}

$\bigotimes$ The authors declare that they have no known competing financial interests or personal relationships that could have appeared to influence the work reported in this paper.

$\square$ The authors declare the following financial interests/personal relationships which may be considered as potential competing interests: 